\title{
Preparation and characterization of colloidal copper xanthate nanoparticles
}

\begin{tabular}{|r|l|}
\hline Journal: & New Journal of Chemistry \\
\hline Manuscript ID & NJ-ART-10-2015-002964 \\
\hline Article Type: & Paper \\
\hline Date Submitted by the Author: & $24-$ Oct-2015 \\
\hline Complete List of Authors: & $\begin{array}{l}\text { Mikhlin, Yuri; Russian Academy of sciences, Institute of Chemistry and } \\
\text { Chemical Technology of Siberian Branch of RAS; } \\
\text { Vorobyev, Sergey; Russian Academy of sciences, Institute of Chemistry } \\
\text { and Chemical Technology of Siberian Branch of RAS; Siberian Federal } \\
\text { University } \\
\text { Saykova, Svetlana; Siberian Federal University, } \\
\text { Tomashevich, Yevgeny; Russian Academy of sciences, Institute of } \\
\text { Chemistry and Chemical Technology of Siberian Branch of RAS } \\
\text { Fetisova, Olga; Russian Academy of sciences, Institute of Chemistry and } \\
\text { Chemical Technology of Siberian Branch of RAS } \\
\text { Kozlova, Svetlana; Russian Academy of sciences, Institute of Chemistry } \\
\text { and Chemical Technology of Siberian Branch of RAS } \\
\text { Zharkov, Sergey; Kirensky Institute of Physics SB RAS; Siberian Federal } \\
\text { University }\end{array}$ \\
\hline
\end{tabular}




\title{
Journal Name
}

\section{ARTICLE}

\section{Preparation and characterization of colloidal copper xanthate nanoparticles}

Received 00th January 20xx, Accepted 00th January 20xx

DOI: $10.1039 / \times 0 \times x 00000 x$

www.rsc.org/

\author{
Yu. Mikhlin, ${ }^{\text {a }}$ S. Vorobyev, ${ }^{\mathrm{a}, \mathrm{b}}$ S. Saikova, ${ }^{\mathrm{b}}$ Ye. Tomashevich, ${ }^{\mathrm{a}}$ O. Fetisova, ${ }^{\mathrm{a}}$ S. Kozlova ${ }^{\mathrm{a}}$ and S. \\ Zharkov ${ }^{\mathrm{b}, \mathrm{c}}$
}

\begin{abstract}
Despite the important role of metal xanthates in a number of industrial processes and emerging applications, no attempts have been made to prepare the nanoparticles and to study colloidal solutions of insoluble heavy metal xanthates, in particular, copper. Here, we examined the formation of copper xanthate colloidal particles in reaction of aqueous solutions of cupric sulfate and various potassium xanthates, and characterized the products using UV-vis absorption, dynamic light scattering (DLS), zeta potential measurement, TEM, electron diffraction, FTIR, thermogravimetry, X-ray photoelectron spectroscopy (XPS), and X-ray absorption spectroscopy (XANES). Colloidal copper xanthates with ROCSSCu composition ( $R$ - ethyl, isopropyl, butyl, isobutyl, amyl groups), disordered structure and the average diameter of $40-80$ $\mathrm{nm}$ easily formed and were stable for several hours, especially if excessive xanthate was used; the hydrodynamic diameter of nanoparticles was smaller at lower temperatures. TEM micrographs and S K- and Cu K-edge XANES revealed core/shell morphology of the particles, probably with $\mathrm{Cu}(\mathrm{I})$ bonded to four $\mathrm{S}$ atoms in the core and reduced copper coordination in the shell. Dixanthogens produced in the reaction along with ROCSSCu, seem to promote the nanoparticle aggregation and precipitate with the copper xanthate, affecting their thermal decomposition.
\end{abstract}

\section{Introduction}

Metal xanthates, salts of the O-esters of carbonodithioic acids and the corresponding O,S-diesters ROCSSH, where stands for alkyl chain R (ethyl-, propyl-, butyl-, etc.), are widely used as collectors in the froth flotation of metal sulfide ores, reagents for heavy metal sedimentation in hydrometallurgy and wastewater treatment, in cellulose synthesis, as vulcanization accelerators in rubber industry, and some others [1-9]. Cytotoxic activity of metal xanthates on human cancer cell has been found [10, 11], however, testing of some compounds, including copper xanthates, has been retarded due to their low solubility [11]. In materials science and nanotechnology, xanthates have been proposed as capping agents for the synthesis of metal nanoparticles and self-assembled monolayers as alternative to thiols, and as sulfidizing reagents for preparation of metal sulfide nanoparticles [12-15]. The interest to metal xanthates as precursors of metal sulfide nanostructures rapidly grows in recent years since the low decomposition temperatures make them compatible with organic polymers for manufacturing of hybrid photovoltaic

Institute of Chemistry and Chemical Technology of the Siberian Branch of the Russian Academy of sciences, Akademgorodok, 50/24,

Krasnoyarsk, 660036, Russia, e-mail: yumikh@icct.ru (Yuri Mikhlin) Siberian Federal University, Svobodny pr. 79, Krasnoyarsk, 660041, Russia

Kirensky Institute of Physics of the Siberian Branch of the Russian Academy of sciences, Akademgorodok 50/38, Krasnoyarsk, 660036, Russia devices [15-19].

The structures and properties of bulk metal xanthates, including copper xanthates, and related substances, their soluble and adsorbed species have been reported in a number of studies (see, in particular, [3, 4, 6, 11, 20-31]. It is well known that the direct interaction of aqueous $\mathrm{Cu}^{2+}$ cations with xanthate ions yields a yellow precipitate of $\operatorname{ROCS}(S) C u$ and dialkyl dixanthogen [20]

\section{$4 \mathrm{ROCSSK}+2 \mathrm{CuSO}_{4}=(\mathrm{ROCSS})_{2}+2 \mathrm{ROCSSCu}$.}

However, to the best of our knowledge, no studies have been aimed at the formation of the nanoparticles and colloids of xanthates of copper or other metal, which could be potentially used as carriers for poorly soluble metal xanthates in several applications, including flotation, biomedicine, materials science. Such a research is also important for understanding the behavior and role of aquatic metal xanthate nanoparticles formed, intentionally or unintentionally, in the flotation slurries, tail dumps and wastewaters of concentrating mills, water treatment systems. It is worth noting that the preparation of metal xanthate nanoparticles, especially for large-scale mineral processing and water treatment, should be easy and cost-effective.

In the current contribution, we describe the formation of colloidal copper xanthate particles via simple mixing of aqueous solutions of cupric sulfate and various potassium xanthates. It was demonstrated that the particles having ROCSSCu composition with an admixture of dixanthogen and 

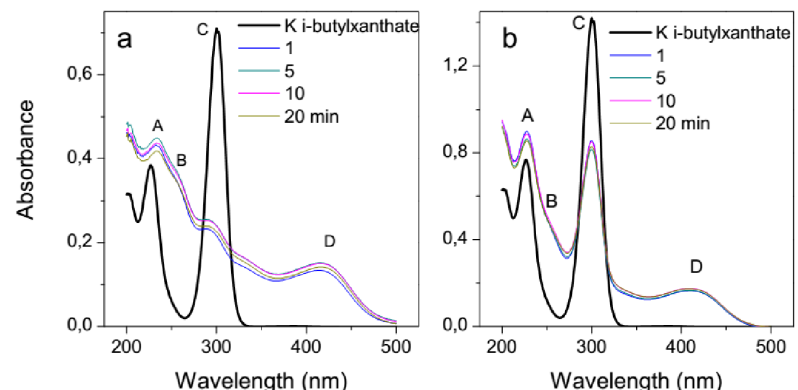

Fig. 1 UV-vis absorption spectra of potassium isobutyl xanthate and the reaction solutions with the xanthate to copper sulfate molar ratios (a) 1.5:1 and (b) $3: 1$ for varying reaction time at $30{ }^{\circ} \mathrm{C}$.

core/shell structure are largely amorphous, and their size and aggregative stability depend mainly upon the initial ratio of the reactants and temperature, the nature of alkyl groups is important too.

\section{Experimental}

\section{Materials and preparation}

Commercial reagents (about $95 \%$ purity) potassium ethyl xanthate $\left(\mathrm{CH}_{3} \mathrm{CH}_{2} \mathrm{OCSSK}\right)$, isopropyl xanthate $\left(\mathrm{C}_{2} \mathrm{H}_{6} \mathrm{CHOCSSK}\right)$, n-butyl xanthate and isobutyl xanthate $\left(\mathrm{C}_{3} \mathrm{H}_{7} \mathrm{CH}_{2} \mathrm{OCSSK}\right)$, and amyl xanthate $\left(\mathrm{C}_{4} \mathrm{H}_{9} \mathrm{CH}_{2} \mathrm{OSSK}\right)$ were recrystallized two times in acetone and kept frozen in solid state; their fresh solutions were prepared using double distilled water directly before synthesis. Other chemicals were of analytical grade and were used as received. In a typical experiment of copper xanthate synthesis, $1 \mathrm{ml}$ of $\mathrm{CuSO}_{4}$ solution $(0.3 \mathrm{mM})$ and $1 \mathrm{~mL}$ of potassium xanthate solution, which concentration varied from $0.15 \mathrm{mM}$ to $12 \mathrm{mM}$ in order to obtain a predetermined $\mathrm{Cu}$ to xanthate ratio, were added to $1 \mathrm{~mL}$ of water and agitated for 5 $\min$ at a desirable temperature $(\mathrm{pH} \sim 8)$; the reaction mixture became yellow in several seconds. Then the solution was loaded into a cell for UV-vis absorption spectroscopy, dynamic light scattering (DLS), or zeta potential measurements. The copper xanthate samples for spectroscopic examination (FTIR, XPS and X-ray absorption spectroscopy) and thermogravimetric analysis were precipitated from the $1 \mathrm{mM}$ colloidal solutions or from more concentrated solutions with the same reagent ratios by centrifugation at $10 \mathrm{xg}$ for $20 \mathrm{~min}$, washed with water by decantation, and dried in air. Some samples were washed with acetone in order to remove dixanthogen.

\section{Characterization}

UV-vis absorption spectra were collected employing an Evolution 300 instrument (Thermo Scientific) in a thermostatic $1 \mathrm{~cm}$ quartz cell; when necessary, the solutions were diluted with water. DLS and zeta potential studies were conducted using Zetasizer Nano ZS spectrometer (Malvern Instruments Ltd, UK) at scattering angle $173^{\circ}$ at a desired temperature in a folded polystyrene cell or polycarbonate cell with $\mathrm{Pd}$ electrodes. The volume weighted mean size $\left(Z_{\mathrm{av}}\right)$ was normally considered in this study due to its high reliability.

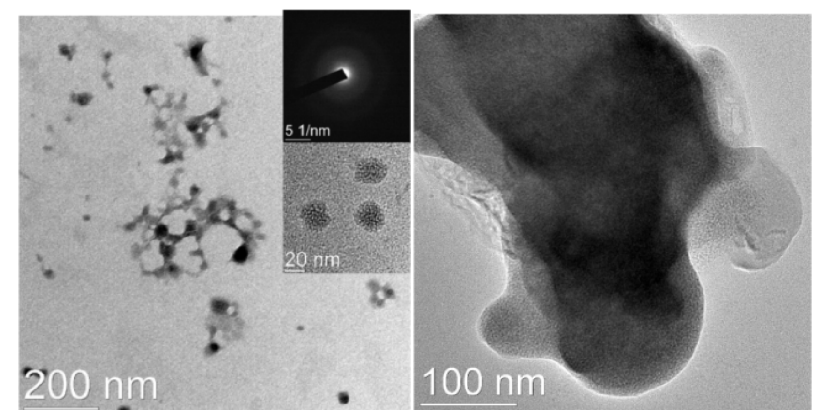

Fig. 2 Typical TEM micrographs and electron diffraction pattern of hydrosol prepared using the potassium isobutyl xanthate to $\mathrm{CuSO}_{4}(1 \mathrm{mM})$ molar ratio of 4 at room temperature and the sample precipitated from the $0.1 \mathrm{M}$ solution (right).

Transmission electron microscopy experiments were performed with a JEM-2100 microscope (JEOL) operating at $200 \mathrm{kV}$. Samples were prepared by placing a hydrosol droplet on a carbon coated copper grid and allowing the solvent to evaporate at room temperature. FTIR spectra were recorded on a Bruker Vector 22 Fourier spectrometer in $\mathrm{KBr}$ pellets. Thermogravimetric (TG) and differential thermal analysis from ambient temperature to $900{ }^{\circ} \mathrm{C}$ was performed using STA449 F1 Jupiter instrument (Netzsch) at heating rate of $10^{\circ} \mathrm{C} \mathrm{min}^{-1}$ in air or argon at a gas flow rate of $50 \mathrm{~mL} \mathrm{~min}^{-1}$.

$X$-ray photoelectron spectra were collected from the precipitate attached to a conducting carbon tape with a SPECS instrument equipped with a PHOIBOS 150 MCD 9 hemispherical analyzer at electron take-off angle $90^{\circ}$. The monochromatized Al K $\alpha$ excitation (1486.6 eV) was used for; the analytical chamber pressure was in the range of $10^{-9} \mathrm{mBar}$. The binding energies were corrected using the $C 1$ s reference $(285.0 \mathrm{eV})$ from aliphatic carbon; a low-energy electron flood gun was employed to eliminate inhomogeneous electrostatic charging of the samples. The spectra were fitted using Gaussian-Lorentzian peak profiles after Shirley background subtraction with CasaXPS software.

$\mathrm{Cu} \mathrm{K}$-edge and S K-edge X-ray absorption spectra were acquired at the KMC-1 dipole beamline (BESSY II synchrotron radiation facility, Helmholtz Zentrum Berlin) using the HIKE endstation with $\mathrm{Si}(111)$ crystal as monochromator simultaneously in total electron yield (TEY) and fluorescence yield (FY) modes. The measurements were carried out in a UHV chamber with a vacuum better than $1 \times 10^{-8} \mathrm{mBar}$ at room temperature.

\section{Results and discussion}

Fig. 1 shows typical electronic absorption spectra of initial xanthate solutions and the reaction media. The spectrum of xanthate displays absorption maxima $A$ at $227 \mathrm{~nm}$ and $\mathrm{C}$ at 300 $\mathrm{nm}$, which should be assigned to $n-\sigma^{*}$ electron transition of $\mathrm{C}=\mathrm{S}$ group and the $\pi-\pi^{*}$ transition of $\mathrm{O}-\mathrm{C}-(\mathrm{S}) \mathrm{S}$ moieties $[22,29$, 30], respectively. These maxima decreased or disappeared, depending on the excess of xanthate in the reaction solution, and the new ones $B$ at $256 \mathrm{~nm}$ originating from altered C-S bonding, and broad maxima $D$ at $420-430 \mathrm{~nm}$ determining the 


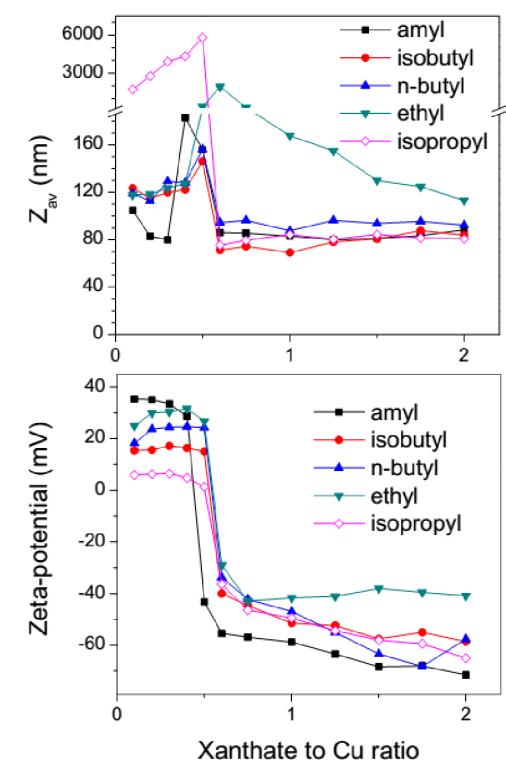

Fig. 3 Effect of molar reactant ratios on the hydrodynamic diameter and zeta potential of copper xanthates for xanthates with various alkyl chains after 15 min reaction (20 $\left.{ }^{\circ} \mathrm{C}\right)$.

yellow color of the hydrosol from S - Cu bonds emerged. The transformations occurred in several seconds and then the spectra changed very little till precipitation of yellow copper xanthate took place after the time, usually few hours, depended on the mixture composition and temperature.

Representative TEM micrographs and selected area electron diffraction patterns (Fig. 2) demonstrate the formation of $30-80 \mathrm{~nm}$ particles tending to aggregation, at least upon drying the hydrosol, bridged possibly with residual dixanthogen. Closer examination of the images (see insertion) suggests that the nanoparticles are constructed of a denser core and about 5-10 nm thick shell. Broad diffuse rings were observed in electron diffraction pattern at approximately 0.12 $\mathrm{nm}$ and $0.2-0.25 \mathrm{~nm}$; the first value is close to typical interatomic C-O and C-S distances in xanthate anion and the second one is typical for the alkyl chain length and Cu-S bonding $[3,25]$. In general, the electron diffraction patterns are indicative of poor crystalline or amorphous structure of the particles. Precipitates from more concentrated solutions consist of mainly irregular 200-400 nm particles (right image).

Fig. 3 shows average hydrodynamic diameters $\left(Z_{a v}\right)$ and zeta-potentials of the reaction products for various xanthates after 15 min reaction as a function of their concentration. The size of the particles was about $120 \mathrm{~nm}$ in the media with the xanthate to copper ratios less than 0.5 , passed maxima at the molar ROCSSK to $\mathrm{CuSO}_{4}$ proportion of 0.5 and fell to less than $100 \mathrm{~nm}$ when excessive xanthates were added. The dimensions are in a reasonable accord with those observed using ex situ TEM. Zeta potentials were positive at the reactant ratios $\leq 0.5$ and sharply decreased with increasing the content of xanthates. Such a behavior concurs with the abovementioned reaction of $\mathrm{Cu}^{2+}$ ions with two xanthate molecules $[1-4,20,21]$, yielding copper xanthate and dixanthate. The positive surface charge of the particles prepared using overstoichiometric quantities of cupric ions seems to induce the

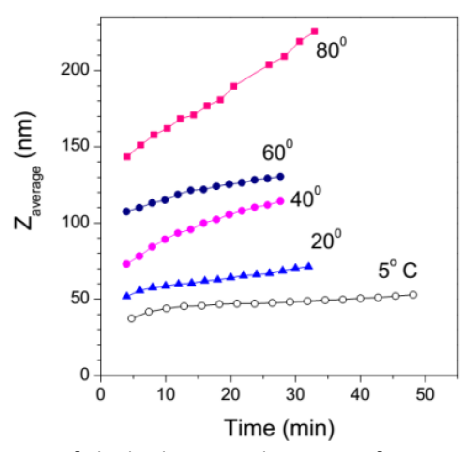

Fig. 4 Time evolution of hydrodynamic diameter of copper isobutyl xanthate nanoparticles at various temperatures. Initial xanthate to copper molar ratio of 4 .

aggregation into micrometer entities while the excessive xanthate anions provide negative surface charge of the nanoparticles and their lesser hydrodynamic size. Generally, xanthates with smaller alkyl chains exhibit lower zeta-potential magnitude and form larger particles, especially in the copperexcessive media, and the situation is not straightforward at the xanthate to copper ratios above 0.5 . Interestingly, the largest particles were obtained with ethyl xanthate. The mechanisms behind these phenomena are not quite clear; it cannot be ruled out that impurities remaining after xanthate purification or/and formed due to the reagent decomposition [1-4, 22] may play a role. It is worth noting that somewhat different and less reproducible results (not in Figures) were obtained in experiments with commercial xanthates, which were used as received; this should be taken into account when cheap commercial reagents are employed without additional purification, for example, in flotation practice.

The influence of reaction temperature and time on the particle size is illustrated in Fig. 4 for copper isobutyl xanthate. One can see that the differences in the hydrodynamic diameter arose in first seconds of the reaction, and the particles grow faster at higher temperatures. Usually, the effect of temperature was less pronounced if more extra xanthate was added, suggesting that aggregation of nanoparticles is at least one of the reasons of the particle growth.

Thermogravimetric analysis of the copper butyl xanthate as an example (Fig. 5) showed that the sample separated by centrifugation lost $\sim 75$ mass.\% at about $190{ }^{\circ} \mathrm{C}$, and the sample treated then with acetone for dixanthogen removing lost about 60 mass.\% at the temperature by 10 degree higher. The main weight difference was due to evaporation of about 15 mass.\% of the dixanthogen admixture at $160-170{ }^{\circ} \mathrm{C}$, both in air and under inert atmosphere. The copper sulfides produced by the xanthate decomposition, which exhibited somewhat behavior in air between $260{ }^{\circ} \mathrm{C}$ and $800{ }^{\circ} \mathrm{C}$ (not shown in the Fig. 5), require further investigation that is beyond the framework of the current article.

FTIR spectra (Fig. 6) of the samples obtained from the solutions with various concentrations and ratios of reagents, including those with excessive $\mathrm{Cu}^{2+}$ ions, were very similar, indicating that the particles have the same bulk composition and structure, and their diverse behavior in solutions (Fig. 3 ) is 


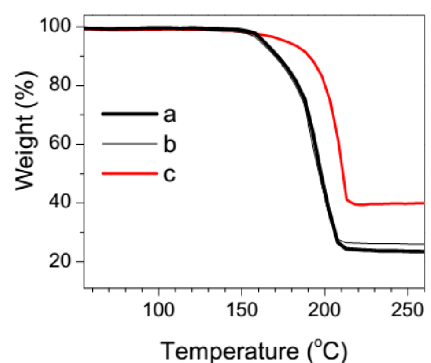

Fig. 5 TGA profiles for the copper $n$ - butyl xanthate $(a, b)$ precipitated via centrifugation and (c) the sample treated with acetone for removing the admixture of dibutyl dixanthogen in air $(a, c)$ and $\operatorname{Ar}(b)$ atmosphere.

due to interfacial phenomena. The spectra from the copper xanthates, and dixanthogen and potassium xanthate as reference materials coincide with those reported by Little and co-workers [21] and confirm the presence of dixanthogen in the precipitated samples.

Dixanthogens evaporated under ultra-high vacuum conditions of XPS experiment, and the elemental concentrations of the copper xanthates derived from the photoelectron spectra (in particular, for copper n-butyl xanthate, at. \%: Cu 8.5, S 17, O 14.8, C 59.6) approaches the $\mathrm{Cu}$ to $\mathrm{S}$ ratio of 1 to 2 and so the ROCSSCu composition, taking in mind an inevitable surface contamination by carbon and oxygen-bearing species. The $\mathrm{Cu} 2 \mathrm{p}$ spectra (Fig. 7) with $\mathrm{Cu}$ $2 p_{3 / 2}$ peak at $932.9 \mathrm{eV}$, no shake-up satellites at $944-948 \mathrm{eV}$, and Auger $\mathrm{Cu} \mathrm{L}_{3} \mathrm{MM}$ peak position at $916 \mathrm{eV}$ mean that copper occurs as $\mathrm{Cu}(\mathrm{I})$ [32-36]. The $\mathrm{S} 2 \mathrm{p}$ band can be fitted using the principal component with the $S 2 p_{3 / 2}$ binding energy at 162.3 $\mathrm{eV}$ and a minor one at $164.3 \mathrm{eV}$ (about 5 relat. \%); the latter may be attributed to bridging sulfur atoms in residual dixanthogen [36, 37] uptaken by the disordered cuprous xanthate. The $C$ 1s spectrum diverges from that of potassium xanthate, which contains the lines of aliphatic carbon at 285.0 $\mathrm{eV}$, and equal intensity of the bands at about $286.5 \mathrm{eV}$ (R-C-O-) and $288 \mathrm{eV}\left(-\mathrm{O}-\mathrm{C}-\mathrm{SS}^{-}\right)$[36, 37], possibly, because the xanthate radical in the surface layers of the particles is oriented outward or due to adsorption of products of xanthate oxidation (particularly, butanol) and carbon contaminants, and some copper xanthate surface decay in vacuum under $\mathrm{X}$-ray irradiation. Akin to FTIR, the photoelectron spectra acquired from the samples prepared with an excess or deficit of xanthate and at various concentrations of the reagents were essentially the same, and, on the whole, agreed with those reported for cuprous xanthates previously [6, 33, 36].

Fig. 8 shows $\mathrm{S}$ K-edge and $\mathrm{CU}$ K-edge XANES spectra measured both in the surface-sensitive TEY mode, which are noisy because of poor conductivity of the material, and in the fluorescence mode (FY) having larger probing depth. The TEY and FY spectra of sulfur are rather similar with the two absorption peaks at $2470 \mathrm{eV}$ and $2471.7 \mathrm{eV}$ attributable to electron transitions from $\mathrm{S} 1 \mathrm{~s}$ to $\sigma^{*} \mathrm{~S}-\mathrm{Cu}$ states and $\mathrm{S}-\mathrm{C}$ states with p-character, respectively [38-40]. A bump at about $2480 \mathrm{eV}$ originates from oxidized surface sulfur species alike sulfate. In contrast, the CU K-edge XANES spectra in TEY and FL

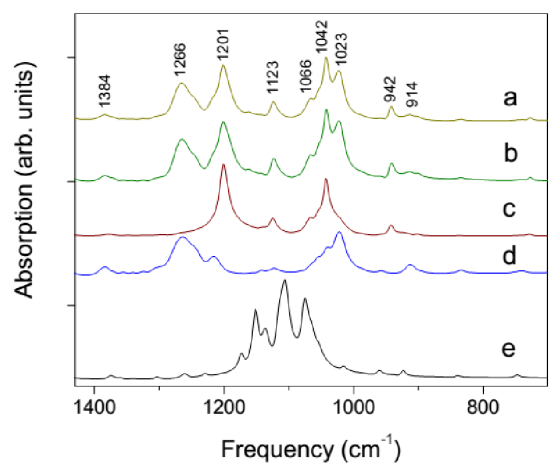

Fig. 6 FTIR spectra of (a) copper n-butyl xanthate prepared with copper to xanthate ratio of (a) 1 to 1.5 and (b) 1 to 0.375 , (c) sample (a) washed with acetone, (d) dibutyldixanthogen, and (e) potassium n-butyl xanthate.

modes, and so the state of copper in the near-surface layer and in the particle bulk clearly differ, with the FY spectrum being close to the Cu K-XANES of cuprous xanthate reported by Pattrick et al. [33]. We may hypothesize on base of earlier spectroscopic studies [32, 33, 41-44] that $\mathrm{Cu}$ atoms in the core are 4-fold coordinated to $S$ and bear a lower positive charge, while the coordination number of copper (I) within the shell is smaller and the local charge is larger. This agrees with the studies on the crystalline binary copper xanthates $[25,45,46]$, in which the copper atom has been reported to exist either in a distorted tetrahedral $\mathrm{S}_{4}$ environment [45], or in $\mathrm{CuS}_{3}$ units [46]. Further studies are necessary to elucidate these disordered structures.

So, the direct interaction between cupric ions and various xanthates in aqueous solution without capping agents or additional reagents produces copper xanthate colloids, which are stable at the concentrations of copper less than $10 \mathrm{mM}$. The surface properties of the particles and their colloidal stability greatly depends on the initial copper to xanthate ratio, while the bulk composition remains essentially the same, including the particles precipitated from more concentrated solutions. Dixanthogen, which is another main reaction product poorly soluble in water, forms droplets charged negatively (to be published in detail elsewhere), which should interact more strongly with copper xanthate particles positively charged in the media with excessive copper ions than with negatively charged ones in the presence of excessive xanthate anions. Dixanthogen partially co-precipitates together with copper xanthate, covering and bridging the nanoparticles and affecting their properties. Up to a few per cent of dixanthogen may be incorporated in the copper xanthate particles, disordering their structure. It is interesting, in particular, that the copper butyl xanthate precipitate containing some dixanthogen decomposes at a lower temperature than that after extraction of dixanthogen.

The phenomena and species described above should play a role in the transport of copper xanthates in the environment, technological or biological media. The findings should be taken into account or implemented in several fields, including flotation practice, water treatment, manufacturing of copper xanthate and copper sulfide nanostructures for various applications. 

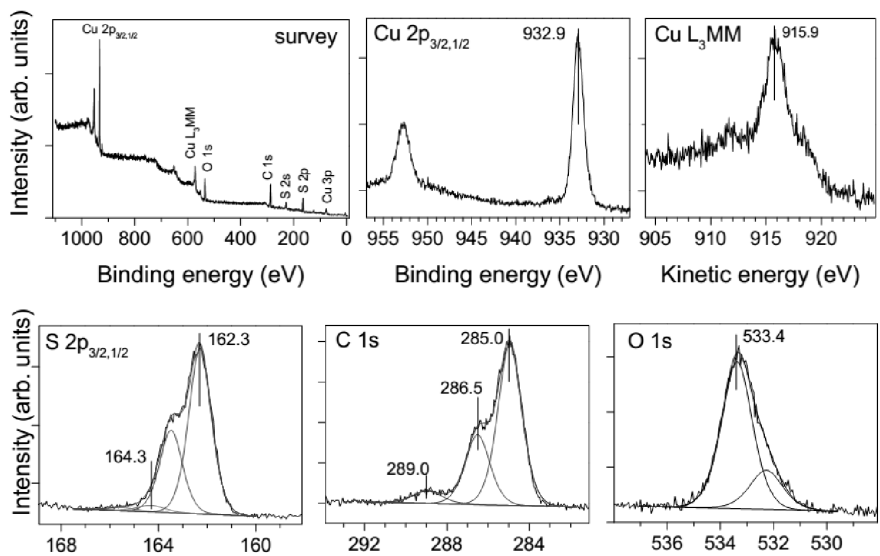

Binding energy (eV)

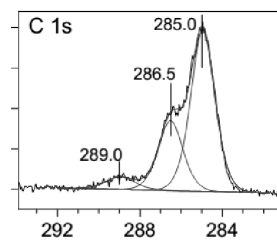

Binding energy $(\mathrm{eV})$ Fig. $7 \mathrm{X}$-ray photoelectron spectra of copper $n$-butyl xanthate.

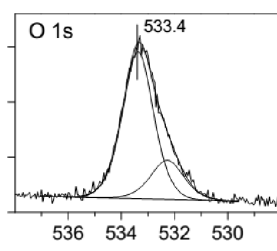

Binding energy (eV)

\section{Conclusions}

It has been demonstrated for the first time that colloidal copper (I) xanthate nanoparticles having the composition ROCSSCu ( R - ethyl, isopropyl, butyl, amyl groups) and the diameter of $40-80 \mathrm{~nm}$ can be simply formed by mixing of aqueous solutions of cupric sulfate and potassium xanthates. The UV-vis spectra evidenced fast appearance of absorption maximum at about $430 \mathrm{~nm}$, suggested that the reaction was largely completed in less than $1 \mathrm{~min}$. A sharp change in zeta potential and hydrodynamic diameter of the particles occurred at the xanthate to cupric ion molar ratio of 0.5 corresponding to the reaction stoichiometry. The particles produced using excessive xanthate concentration had high negative zeta potential magnitude, lower diameter and higher stability than the ones charged positively at the excess of cupric ions. The smaller particles emerged and grew more slowly at lower temperatures. Characterization of copper xanthates prepared using various concentrations and ratios of the reagents found that the particles had very similar composition. IR spectroscopy and thermogravimetric analysis demonstrated that the precipitated material comprised dixanthogen (an order of 15 mass. \%), which possibly promoted aggregation of the colloidal copper xanthate, especially in the solutions with excessive copper ions, and decreased the temperature of thermal decomposition of the precipitates. XPS data suggested that minor dixanthogen may be incorporated in the disordered particles. TEM micrographs, electron diffraction and $\mathrm{S} \mathrm{K}$ - and $\mathrm{CU}$ K-edge XANES spectra collected in TEY and FY modes revealed a core/shell structure of the particles, showing probably reduced coordination and somewhat increased local positive charge of $\mathrm{Cu}$ atoms in the shell in comparison with the copper in a distorted tetrahedral coordination with four $\mathrm{S}$ atoms in the core.

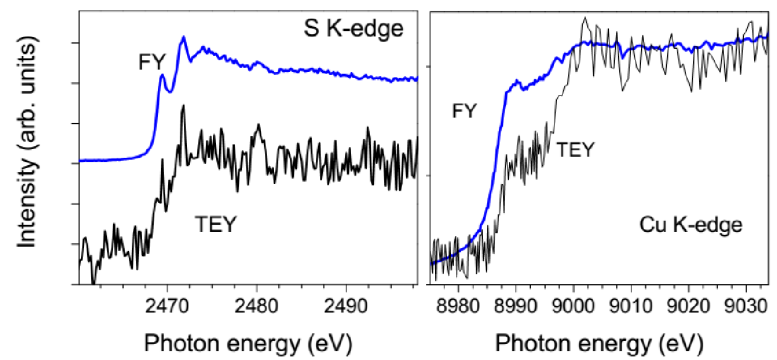

Fig. 8 X-ray absorption S-K and CU K-XANES spectra collected in TEY and fluorescence yield modes from copper $n$-butyl xanthate precipitate.

\section{Acknowledgements}

This research was supported by the Russian Science Foundation, grant 14-17-00280. We thank Dr. Roberto Felix Duarte (HZB) and bilateral program "German-Russian laboratory at BESSY II for assistance with the X-ray absorption experiments.

\section{Notes and references}

1 S. R. Rao, Xanthate and Related Compounds, Marcel Dekker, New York, 1971.

2 G. Winter, Reviews in Inorganic Chemistry, 1980, 2, 253.

3 E. R. T. Tiekink and G. Winter, Reviews in Inorganic Chemistry, 1992, 12, 183.

4 G. H. Harrison, Xanthates. In: Kirk-Othmer Encyclopedia of Chemical Technology, M. Howe-Grant (Ed.), John Wiley \& Sons, New York, pp. 713-734, 1998.

5 S. M. Bulatovic, Handbook of Flotation ReagentsChemistry, Theory and Practices, vol.1 - Flotation of sulfides ores, Elsevier, Amsterdam, 2007.

6 A. P. Chandra, L. Puskar, D. J. Simpson and A. R. Gerson, Int. J. Miner. Proc. 2012, 114-117, 16.

7 Y.-K. Chang, J.-E. Chang, T.-T. Lin and Y.-M. Hsu, J. Hazard. Mater., 2002, B94, 89.

8 S. Chakraborty and V. Tare, Bioresource Technol., 2006, 97, 2407.

9 M. R. Mahmoud, N. K. Lazaridis and K. A. Matis, Process Safety and Environmental Protection, 2015, 94, 203.

10 W. Friebolin, G. Schilling, M. Zöller and E. Amtmann, J. Med. Chem., 2004, 47, 2256.

11 W. Friebolin, G. Schilling, M. Zöller and E. Amtmann, J. Med. Chem., 2005, 48, 7925.

12 S. Efrima and N. Pradhan, C. R. Chimie, 2003, 6, 1035.

13 H. J. Moore, R. Colorado, Jr., H .J. Lee, A. C. Jamison and T. R. Lee, Langmuir, 2013, 29, 10674.

14 N. Pradhan, B. Katz and S. Efrima, J. Phys. Chem. B, 2003, 107, 13843.

15 H. C. Leventis, S. P. King, A. Sudlow, M. S. Hill, K. C. Molloy and S. A. Haque, Nano Lett., 2010, 10, 1253.

16 T. Rath, C. Padeste, M. Vockenhuber, C. Fradler, M. Edler, A. Reichmann, I. Letofsky-Papst, F. Hofer, Y. Ekinci and T. Griesser, J. Mater. Chem. A, 2013, 1, 11135.

17 A. Rabkin, O. Friedman and Y. Golan, J. Colloid Interf. Sci., 2015, 457, 43.

18 E. A. Lewis, P. D. McNaughter, Z. Yin, Y. Chen, J. R. Brent, S. A. Saah, J. Raftery, J. A. M. Awudza, M .A. Malik, P. O'Brien and S. J. Haigh, Chem. Mater., 2015, 27, 2127. 
19 A. Fischereder, A. Schenk, T. Rath, W. Haas, S. Delbos, C. Gougaud, N. Naghavi, A. Pateter, R. Saf, D. Schenk, M. Edler, K. Bohnemann, A. Reichmann, B. Chernev, F. Hofer and G. Trimme, Monatsh Chem., 2013, 144, 273.

20 M. P. Matuszak, J. Am. Chem. Soc., 1931, 53, 4451.

21 G. H. Little, G. W. Poling and J. Leja. Can. J. Chem., 1961, 39, 745.

22 N. Sheikh, The chemical stability of heavy metal xanthates. PhD Thesis, Univ. British Columbia, 1972.

23 R. Woods, G.A. Hopes and G.M. Brown, Colloids Surf. A, 1998, 137, 329.

24 S. S. Garje and V. K. Jain, Coord. Chem. Rev., 2003, 236, 35.

25 E. R. T. Tiekink and I. Haiduc, Progr. Inorg. Chem., 2005, 54, 127.

26 A. O. Görgülü, M. Arslan and E. Çil, J. Coord. Chem., 2006, 59, 1913.

27 P. Hellstrom, S. Oberg, A. Fredriksson and A. Holmgren, Spectrochim. Acta, 2006, 65A, 887.

28 D. Rusanova, K. E. Christensen, I. Persson, K. J. Pike, O. N. Antzutkin, X. Zou, R. Dupree and W. Forsling, J. Coord. Chem., 2007, 60, 517.

29 B. Bag, B. Das and B. K. Mishra, Miner. Eng., 2011, 24, 760.

30 L. C. Juncal, Y. A. Tobón, O. E. Piro, C. O. Della Vèdova and R. M. Romano, New J. Chem., 2014, 38, 3708.

31 T. C. Vagvala, S. S. Pandey, Y. Ogomi, T. Ma and S. Hayase, Inorg. Chim. Acta, 2015, 435, 292.

32 R .A. D. Pattrick, J .F. W. Mosselmans, J. M. Charnock, K. E. R. England, G. R. Helz, C. D. Garner and D. J. Vaughan, Geochim. Cosmochim. Acta, 1997, 61, 2023.

33 R. A. D. Pattrick, K. E. R. England, J. M. Charnock and J. F. W. Mosselmans, Int. J. Miner. Proc., 1999, 55, 247.

34 S. W. Goh, A. N. Buckley, W. M. Skinner and L.-J. Fan, Phys. Chem. Minerals, 2010, 37, 389.

35 S. Saikova, S. Vorobyev, M. Likhatski, A. Romanchenko, S. Erenburg, S. Trubina and Yu. Mikhlin, Appl. Surf. Sci., 2012, 258, 8214.

36 A. V. Shchukarev, T. O. Nichiporenko and G. N. Mashevskiy, Obogashchenie rud, 1992, 1, 21 (in Russian).

37 I. Kartio, K. Laajalehto, E. Suoninen, S. Karthe, R. Szargan, Surf. Interface Anal., 1992, 18, 807; R. Szargan, S. Karthe, E. Suoninen, Appl. Surf. Sci., 1992, 55, 227.

38 D. Li, G. M. Bancroft, M. Kasrai, M. E. Fleet, X. H. Feng, B. X. Yang and K. H. Tan, Phys. Chem. Miner., 1994, 21, 317.

39 R. Chauvistré, J. Hormes, E. Hartmann, N. Etzenbach, R. Hosch and J. Hahn, Chem. Phys., 1997, 223, 293.

40 T. Tsuduki, A. Imanishi, K. Isawa, S. Terada, F. Matsui, M. Kiguchi, T. Yokoyama and T. Ohta, J. Synchrotron Radiation, 1999, 6, 787.

41 L.-S. Kau, D. J. Spira-Solomon, J. E. Penner-Hahn, K. O. Hodgson and E. I. Solomon, J. Am. Chem. Soc., 1987, 109, 6433.

42 J. R. Vegelius, K. O. Kvashnina, H. Hollmark, M. Klintenberg, Y. O. Kvashnin, I. L. Soroka, L. Werme and S. M. Butorin, J. Phys. Chem. C, 2012, 116, 22293.

43 P. Kumar, R. Nagarajan and R. Sarangi, J. Mater. Chem. C, 213, 1, 2448.

44 A. S. Jullien, C. Gateau, I. Kieffer, D. Testemale and P. Delangle, Inorg. Chem., 2013, 52, 9954.

45 K. Tang, X. Jin, Y. Long, P. Cui, Y.Tang, J. Chem. Res. (S), 2000, 2000, 452.

46 C. Wycliff, D. S. Bharathi, A. G Samuelson and M. Nethaji, Polyhedron, 1999, 18, 949. 
Colloids formed via direct interaction of aqueous $\mathrm{Cu}^{2+}$ ions and xanthates and their precipitates incorporating dixanthogen were characterized
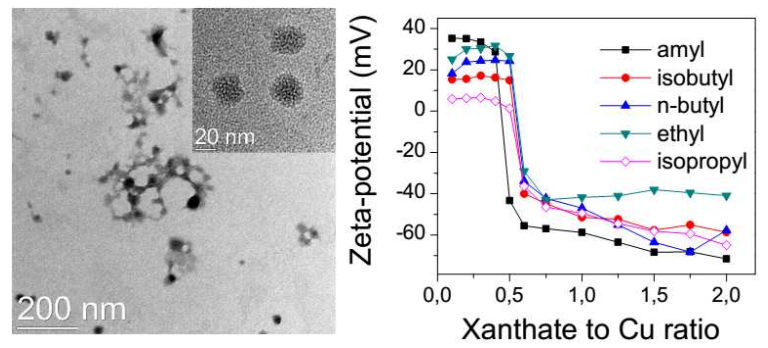